\title{
ORT.32 - The anti-vaccination meanings: an analysis on risks, responsibilities and positioning of subjects
}

\author{
Renata Ribeiro Gomez de Souza ${ }^{1 *}$; Igor Sacramento ${ }^{2}$. \\ 1Fiocruz/Bio-Manguinhos; \\ 2Fiocruz/ICICT.
}

Introduction: In Brazil, vaccination coverage has remained historically high [1], especially in 2016, as reported by the Institute for Health Metrics and Evaluation (IHME) of the University of Washington, published in The Lancet journal. This changed as of 2017, when there was a 400\% increase in measles cases in European countries: 21 thousand people infected and 35 deaths and also marked decreases in vaccination coverage in Brazil[2]. One of the hypotheses for this reduction is the increasingly strong role of the anti-vaccine movement, which is considered one of the greatest health challenges of the WHO for 2019[3].

[1] http://agenciabrasil.ebc.com.br/internacional/noticia/2017-09/brasil-e-um-dos-paisescom-maior-cobertura-de-vacinacao

Objective: To identify the main current motivations, concerns and themes, besides the identities that are being constituted in discursive practices in a public, open, Brazilian antivaccination group in the largest social network, Facebook.

Methodology: To conduct a quantitative-qualitative (YIN, 2015) case study of systematic and non-participant observation (MALHOTRA, 2001), we opted for the choice of an open group, "O lado obscuro das vacinas [The dark side of vaccines]" among 148 similar, taking into account the criteria of frequency of postings and activity of group members. In a second moment, the 10 most liked posts were selected from among the 12,895 messages Data was obtained with the Netvizz Tool, a free Facebook application for collection of postings from closed groups. As the topics were listed, the personal profiles, their performance and the most recurrent themes were analyzed exhaustively, using the proposal of Fairclough (2001).

Results: After creating the categories of profiles and risk analysis and motivators of the antivaccination posts, a qualitative analysis of the 10 most liked posts was conducted, published by mothers, with the motivation to exchange information about vaccines, weighing risks and benefits. At the same time, the most recurrent themes from the most liked posts were quantified, which were adverse events of the vaccine, legal aspects of the immunization policy (child and adolescent statute, obligation to keep vaccination up to date, including as a requirement for attending schools, crossing borders); prevailing anti-vaccine defense.

Conclusion: In the specific case of this work, the analysis of an anti-vaccination group on Facebook did not confirm the hypothesis of religious or vegan motivation, whereas the fact that its size has tripled (in April 2016, the group had 3,900 members and a year after, 12,500 members) may be related to the outbreak period of yellow fever and the existence of antivaccine rumors in the press and social networks.

Keywords: risk; communication; anti-vaccination 